\title{
Jaringan Syaraf Tiruan dengan Metode Learning Vector Quantization (LVQ) dalam Menentukan Klasifikasi Jenis Tilang Berdasarkan Kendaraan
}

\author{
Winda Usman $^{1}$, Irfan Sudahri Damanik ${ }^{2}$, Jaya Tata Hardinata ${ }^{3}$ \\ STIKOM TUNAS BANGSA \\ Jl. Jend. Sudirman, Blok A No.1, 2, 3, Pematangsiantar \\ windausman1511@gmail.com
}

\begin{abstract}
Learning Vector Quantization (LVQ) is a method of classifying patterns in which each output represents a particular category or class. The author uses the LVQ method to classify the type of ticket based on the vehicle that his research had previously conducted at the Simalungun District Prosecutor's Office. In this study, the author provides a solution to facilitate the filing of ticket data in the Simalungu District Prosecutor's Office, so that the data that has existing tickets can be classified according to their respective types. The results of this study indicate that $L V Q$ is able to classify with an accuracy rate of $76.0 \%$.
\end{abstract}

Keywords : Classification, Ticketing Data, Learning Vector Quantization (LVQ), Artificial Neural Networks, Matlab.

Abstrak- Learning Vector Quantization (LVQ) merupakan suatu metode pengklasifikan pola yang masing-masing output mewakili kategori atau kelas tertentu. Penulis mengguakan metode LVQ untuk mengklasifikasikan jenis tilang berdasarakan kendaraan yang sebelumnya penelitiannya telah dilakukan di Kejaksaan Negeri Simalungun. Dalam penelitian ini, Penulis memberikan solusi untuk mempermudah pemberkasan data tilang yang ada di kantor Kejaksaan Negeri Simalungu, sehingga data yang ada tilang yang ada dapat di klasifikasikan berdasarkan jenisnya masing-masing. Hasil dari penelitian ini menunjukkan bahwa LVQ mampu untuk mengklasifikasi dengan tingkat akurasi sebesar $76.0 \%$.

Kata kunci : Klasifikasi, Data Tilang, Learning Vector Quantization (LVQ), Jaringan Syaraf Tiruan, Matlab.

\section{PENDAHULUAN}

Kecerdasan Buatan AI (Artificial Intelligence) merupakan salah satu bagian dari ilmu komputer yang mempelajari bagaimana membuat mesin (komputer) dapat melakukan pekerjaan seperti dan sebaik yang dilakukan oleh manusia bahkan bisa lebih baik daripada yang dilakukan manusia [1]-[3].Perkembangan teknologi di zaman sekarang ini sangat canggih dan berkembang pesat. Hal ini dapat dibuktikan dengan adanya inovasi yang ada di masa ini. Teknologi komputer juga dapat mengklasifikasikan atau menyusun data secara sistematis. Salah satu teknologi yang bisa menyelesaikan ini adalah Jaringan Syaraf Tiruan (JST). Jaringan Syaraf Tiruan merupakan paradigma pemrosesan suatu informasi yang terinspirasi oleh sistem sel syaraf biologi, sama seperti otak manusia yang memroses suatu informasi [4]-[10]. Ada banyak Perusahaan / Instansi yang masih memiliki kendala dalam mengklasifikasikan data yang mereka miliki. Salah 
satunya dalam mengkalsifikasikan jenis tilang berdasarkan kendaraan. Kendaraan yang di maksud adalah kendaraan bermotor, baik kendaraan roda 2 dan roda 4 .

\section{METODOLOGI PENELITIAN}

Penelitian digunakan untuk mencari atau memperoleh, dan mengumpulkan data, baik data primer maupun data skunder yang diperlukan dalam pembuatan suatu karya ilmiah. Dalam penelitian ini, untuk menyelesaikannya digunakan Jaringan Syaraf Tiruan (JST) dengan metode Learning Vector Quantization (LVQ). LVQ diharapkan dapat menyelesaikan masalah yang timbul dalam Kejaksaan Negeri Simalungun khususnya bagian tilang. dengan tingkat akurasi yang tinggi, kecepatan pemrosesan data, dan menghasilkan output untuk dapat ditindak lanjuti dalam menangani masalah tersebut. Tabel dan Gambar dibuat center seperti di bawah ini dan diacu pada naskah.

Tabel 1. Data Tilang

\begin{tabular}{|c|c|c|c|c|c|c|}
\hline No & Nama & $\begin{array}{l}\text { Jenis } \\
\text { Barang } \\
\text { Bukti }\end{array}$ & $\begin{array}{c}\text { Jenis } \\
\text { Operasi }\end{array}$ & Pasal & Kehadiran & Target \\
\hline 1 & Pelanggar 1 & SIM C & $\begin{array}{l}\text { Oprasi } \\
\text { Zebra }\end{array}$ & $\begin{array}{l}\text { Pasal } 293 \text { ayat (2) Jo Pasal } 107 \\
\text { ayat (2) }\end{array}$ & Hadir & Roda 2 \\
\hline 2 & Pelanggar 2 & SIM A & $\begin{array}{l}\text { Oprasi } \\
\text { Zebra }\end{array}$ & $\begin{array}{l}\text { Pasal } 288 \text { ayat (1) Jo Pasal } 70 \\
\text { ayat (2) }\end{array}$ & Diwakilkan & Roda 4 \\
\hline 3 & Pelanggar 3 & STNK & $\begin{array}{l}\text { Oprasi } \\
\text { Lintas }\end{array}$ & Pasal 281 Jo Pasal 77 ayat (1) & Hadir & Roda 4 \\
\hline 4 & Pelanggar 4 & SIM A & $\begin{array}{l}\text { Oprasi } \\
\text { Zebra }\end{array}$ & Pasal 289 Jo Pasal 106 ayat (6) & Hadir & Roda 4 \\
\hline 5 & Pelanggar 5 & SIM C & $\begin{array}{l}\text { Oprasi } \\
\text { Lintas }\end{array}$ & $\begin{array}{l}\text { Pasal } 293 \text { ayat (2) Jo Pasal } 107 \\
\text { ayat (2) }\end{array}$ & Hadir & Roda 2 \\
\hline 6 & Pelanggar 6 & STNK & $\begin{array}{l}\text { Oprasi } \\
\text { Lintas }\end{array}$ & Pasal 289 Jo Pasal 106 ayat (6) & Hadir & Roda 4 \\
\hline 7 & Pelanggar 7 & STNK & $\begin{array}{l}\text { Oprasi } \\
\text { Lintas }\end{array}$ & Pasal 303 Jo Pasal 137 ayat & Hadir & Roda 4 \\
\hline 8 & Pelanggar 8 & KENDARAAN & $\begin{array}{l}\text { Oprasi } \\
\text { Lintas }\end{array}$ & $\begin{array}{l}\text { Pasal } 288 \text { ayat (1) jo Pasal } 106 \\
\text { ayat (5) huruf a }\end{array}$ & Hadir & Roda 2 \\
\hline 9 & Pelanggar 9 & STNK & $\begin{array}{l}\text { Operasi } \\
\text { Lintas }\end{array}$ & $\begin{array}{l}\text { Pasal } 291 \text { ayat(1) Jo Pasal } 106 \\
\text { ayat(8) }\end{array}$ & $\begin{array}{l}\text { Tidak } \\
\text { Hadir }\end{array}$ & Roda 2 \\
\hline 10 & $\begin{array}{l}\text { Pelanggar } \\
10\end{array}$ & KENDARAAN & $\begin{array}{l}\text { Operasi } \\
\text { Lintas }\end{array}$ & $\begin{array}{l}\text { Pasal } 288 \text { ayat (1) jo Pasal } 106 \\
\text { ayat (5) huruf a }\end{array}$ & $\begin{array}{l}\text { Tidak } \\
\text { Hadir }\end{array}$ & Roda 4 \\
\hline
\end{tabular}

Data diatas kemudian diinisialisasikan kedalam bentuk angka - angka agar dapat dibaca oleh bahasa komputer, khususnya software Matlab yang akan digunakan sebagai software klasifikasi metode Learning Vector Quantization (LVQ).

Tabel 2. Normalisasi DataTilang

\begin{tabular}{|c|c|c|c|c|c|}
\hline No & $\mathbf{X 1}$ & $\mathbf{X 2}$ & $\mathbf{X 3}$ & $\mathbf{X 4}$ & Target \\
\hline 1 & 1 & 1 & 6 & 1 & 1 \\
\hline 2 & 2 & 1 & 3 & 2 & 2 \\
\hline 3 & 3 & 2 & 1 & 2 & 2 \\
\hline 4 & 2 & 1 & 4 & 2 & 2 \\
\hline 5 & 1 & 2 & 6 & 1 & 1 \\
\hline 6 & 3 & 2 & 4 & 2 & 2 \\
\hline
\end{tabular}




\begin{tabular}{|c|c|c|c|c|c|}
\hline No & $\mathbf{X 1}$ & $\mathbf{X 2}$ & $\mathbf{X 3}$ & $\mathbf{x 4}$ & Target \\
\hline 7 & 3 & 2 & 7 & 2 & 2 \\
\hline 8 & 4 & 2 & 3 & 1 & 1 \\
\hline 9 & 3 & 2 & 5 & 1 & 1 \\
\hline 10 & 4 & 2 & 3 & 2 & 2 \\
\hline
\end{tabular}

Keterangan :

$\mathrm{X} 1$ : Jenis Barang Bukti, terdiri dari :

$$
\begin{aligned}
& 1: \text { SIM A } \\
& 2: \text { SIM B } \\
& 3: \text { SIM C } \\
& 4: \text { STNK } \\
& 5: \text { Kendaraan }
\end{aligned}
$$

X2: Jenis Operasi, terdiri dari :

1 : Operasi Zebra

2: Operasi Lintas

3 : Operasi Simpatik

4 : Operasi Lilin

X3: Pasal, terdiri dari :

1 : Pasal 281 Jo Pasal 77 ayat(1)

2 : Pasal 285 ayat(1) Jo Pasal 106 ayat(3)

3 : Pasal 288 ayat(1) Jo Pasal 106 ayat(5) huruf a

4 : Pasal 289 Jo Pasal 106 ayat(6)

5 : Pasal 291 ayat(1) Jo Pasal 106 ayat(8)

6 : Pasal 293 ayat(1) Jo Pasal 107 ayat(1)

7 : Pasal 303 ayat Jo Pasal 137 ayat(4)

X4: Kehadiran Saat Sidang, terdiri dari :

1 : Hadir

2 : Diwakilkan

3 : Tidak Hadir

Target : Jenis Kendaraan, terdiri dari :

1 : Roda 2

2 : Roda 4

\subsection{Jaringan Syaraf Tiruan}

JST adalah prosesor tersebar paralel yang sangat besar dimana memiliki kecenderungan menyimpan pengetahuan yang bersifat pengalaman dan membuatnya siap untuk digunakan. JST menyerupai otak manusia dalam dua hal, yaitu pengetahuan diperoleh dari proses belajar dan kekuatan hubungan antar sel syaraf (neuron) yang dikenal sebagai bobot-bobot sinaptik digunakan untuk menyimpan pengetahuan.

\subsection{Arsitektur Jaringan Syaraf Tiruan}

Jaringan Lapisan Tunggal (Single Layer Network) adalah Jaringan dengan lapisan tunggal terdiri dari 1 lapisan input dan 1 lapisan output. Setiap neuron yang terdapat di dalam lapisan input selalu terhubung dengan setiap neuron yang Klasifikasi Jenis Tilang Berdasarkan Kendaraan (Winda Usman)| 782 
terdapat pada lapisan output. Jaringan ini hanya menerima input kemudian secara langsung akan mengolahnya menjadi output tanpa harus melalui lapisan tersembunyi [11]-[24].

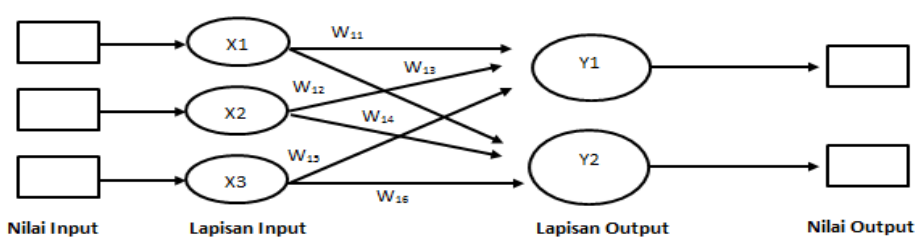

Gambar 1. Arsitektur Lapisan Tunggal

\subsection{Tilang}

Banyak sekali kasus pelanggaran lalu lintas di jalan raya yang dilakukan oleh pemakai jalan yang cenderung mengakibatkan timbulnya kecelakaan dan kemacetan lalu lintas yang semakin meningkat. Pelanggaran lalu lintas mayoritas berupa pelanggaran dalam hal marka, rambu lalu lintas dan lampu pengatur lalu lintas seperti larangan berhenti, parkir di tempat-tempat tertentu, menerobos lampu merah, tanpa surat dan kelengkapan kendaraan, dan lain-lain. Perkembangan jumlah kendaraan bermotor di Indonesia mengalami peningkatan pesat seiring bertambahnya peningkatan alat transportasi bermotor demikian halnya juga terjadi peningkatan pelanggaran lalu lintas[25].

\subsection{Learning Vector Quantization (LVQ)}

Metode Learning Vector Quantization (LVQ) adalah suatu metode pelatihan untuk melakukan pembelajaran pada lapisan kompetitif yang terawasi (supervised learning) yang arsitektur jaringannya berlayer tunggal (single layer). Kelas-kelas yang didapatkan sebagai hasil dari lapisan kompetitif ini hanya tergantung pada jarak antara vektor-vektor input. Jika dua vektor input mendekati sama, maka lapisan kompetitif akan meletakkan kedua vektor input tersebut ke dalam kelas yang sama[26].

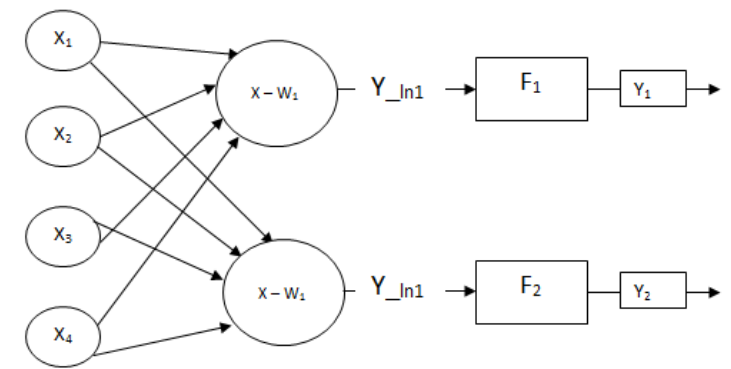

Gambar 2. Arsitektur Jaringan Syaraf Tiruan LVQ

\subsection{Klasifikasi}

Dalam Kamus Besar Bahasa Indonesia (KBBI), kalsifikasi adalah penyusunan bersistem dalam kelompok atau golongan yang menurut kaidah atau standart yang ditetapkan. Klasifikasi juga dapat dikatakan sebagai pembagian sesuatu menurut kelas-kelasnya. Namun, berdasarkan ilmu pegetahuan, klasifikasi adalah proses 
pengklasifikasian benda berdasarkan ciri-ciri persamaan dan perbedaannya. Kata klasifikasi berasal dari bahasa Belanda "classificatie" dan bahasa Prancis "classification".

\subsection{Kerangka Kerja Penelitian}

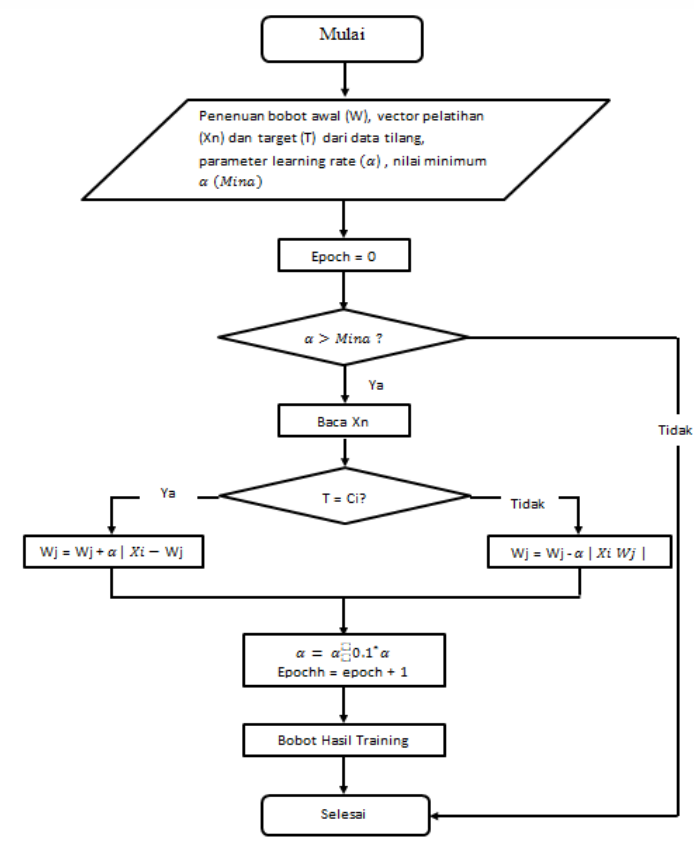

Gambar 3. Arsitektur Algoritma LVQ

Langkah-langkah algoritma pelatihan LVQ terdiri atas ;

1. Inisialisasi bobot awal (W) dan parameter LVQ, yaitu maxEpoch, $\alpha$, dec $\alpha$ dan $\min \alpha$.

2. Masukkan data input (X) dan kelas target (T).

3. Tetapkan kondisi awal: epoch $=0$.

4. Kerjakan jika: (epoch $<$ maxEpoch) dan $(\alpha \geq \min \alpha)$. a. epoch $=$ epoch +1 . $b$. Tentukan J sedemikian hingga $\|\mathrm{Xi}-\mathrm{Wj}\|$.

5. Tes kondisi berhenti dengan output berupa bobot optimal.

\section{HASIL DAN PEMBAHASAN}

\subsection{Analisis}

clear;

close all;

warning off;

\%Proses input data training, data pelatihan dan data target pelatihan

filename = 'Data.xlsx';

sheet $=3$;

xlRange = 'A1:CV4';

$\mathrm{x}=$ xlsread(filename, sheet, $\mathrm{xlRange})$;

filename = 'Data.xlsx'; 
sheet $=5$;

xlRange = 'A1:CV2';

$\mathrm{t}=\mathrm{xlsread}($ filename, sheet, $\mathrm{xlRange}$ );

net $=$ lvqnet $\left(4,0.2,{ }^{\prime}\right)$

net $=\operatorname{train}($ net $, \mathrm{x}, \mathrm{t})$;

view(net)

$\mathrm{y}=\operatorname{net}(\mathrm{x})$;

perf $=\operatorname{perform}($ net $, y, t)$

classes $=\operatorname{vec} 2$ ind $(y)$

\subsection{Hasil}

Penelitian ini menggunakan 3 pola yang di uji coa, antara lain menggunakan pola $4-4-2,4-3-2$, dan $4-2-2$. Dari 3 pola yang di uji coba, pola yang menghasilkan tingkat akurasi terbaik terdapat pada pola $4-4-2$ dengan tingkat akurasi sebesar $76 \%$.

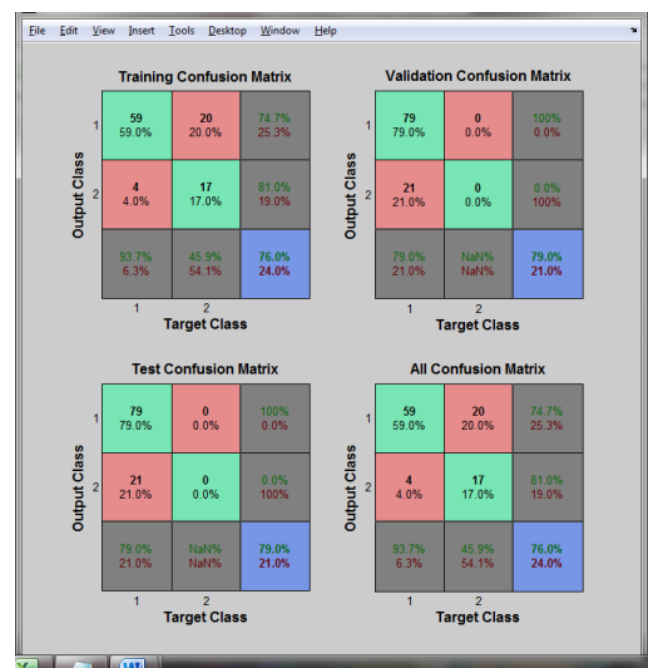

Gambar 4. Cunfusion Pola 4-2 - 2

\section{KESIMPULAN}

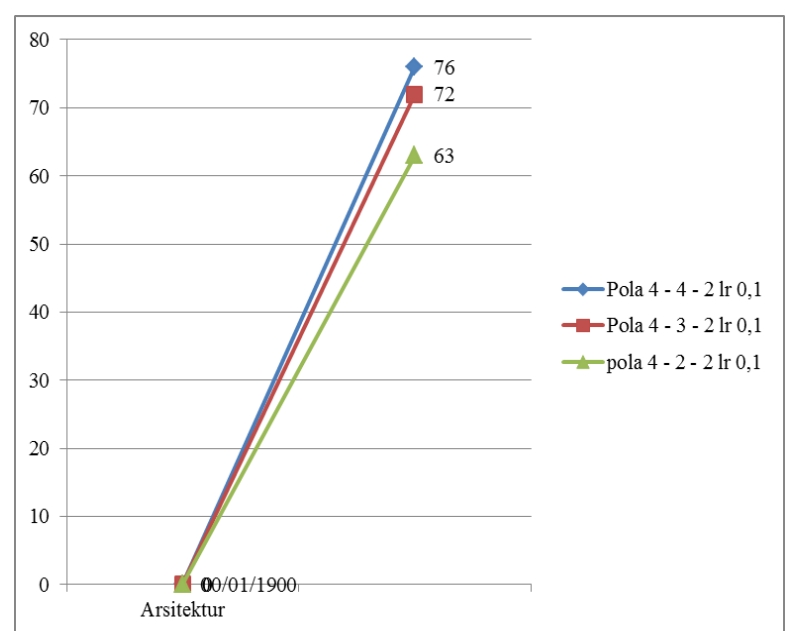

Gambar 5. Grafik Akurasi Pola Jaringan LVQ 
Kesimpulan yang di dapat dari hasil penelitian yang dilakukan dengan proses testing dan training data tilang Kejaksaan Negeri Simalungun nmenggunakan Jaringan Syaraf Tiruan dengan metode Learning Vector Quantization (LVQ) adalah sebagai berikut :

a. Klasifikasi jenis tilang berdasarkan kendaraan dengan menggunakan algoritma $L V Q$ dapat di selesaikan dengan tingkat akurasi $76.0 \%$ dengan pola $4-4-2$ dan learning rate 0,1 .

b. Data tilang di klasifikasikan berdasarkan dua jenis kendaraan, yaitu roda 2 dan roda 4 didukung dengan adanya atribut data yaitu jenis barang bukti, jenis operasi, pasal yang dikenakan, dan kehadiran terdakwa pada saat sidang yang dimasukkan sesuai dengan ketentuan algoritma $L V Q$ untuk mencapai akurasi terbaik.

c. Dalam menentukan arsitektur terbaik algoritma Learning Vector Quantization ( $L V Q$ ) terdiri dari 2 (dua) bagian yaitu proses training dan testing. Data yang ada dimasukkan kedalam pola jaringan yang terdiri dari lapisan input, lapisan output, lapisan tersembunyi, learning-rate dan tingkat error. Pola yang terdapat pada penelitian ini adalah pola $4-4-2$ dengan learning-rate 0.1 yang menghasilkan akurasi sebesar $76.0 \%$, pola $4-3-2$ dengan learning rate 0.1 yang menghasilkan akurasi sebesar $72.0 \%$, dan pola $4-2$ - 2 dengan learningrate 0,1 yang menghasilkan akurasi sebesar 63\%. Hasil akurasi terbaik yang diperoleh adalah dengan menggunakan pola $4-4-2$ learning-rate 0.1 dengan hasil akurasi 76.0\%.

\section{DAFTAR PUSTAKA}

[1] A. Wanto and A. P. Windarto, "Analisis Prediksi Indeks Harga Konsumen Berdasarkan Kelompok Kesehatan Dengan Menggunakan Metode Backpropagation," Jurnal \& Penelitian Teknik Informatika Sinkron, vol. 2, no. 2, pp. 37-44, 2017.

[2] A. Wanto, A. P. Windarto, D. Hartama, and I. Parlina, "Use of Binary Sigmoid Function And Linear Identity In Artificial Neural Networks For Forecasting Population Density," International Journal Of Information System \& Technology, vol. 1, no. 1, pp. 43-54, 2017.

[3] A. Wanto, M. Zarlis, Sawaluddin, and D. Hartama, "Analysis of Artificial Neural Network Backpropagation Using Conjugate Gradient Fletcher Reeves in the Predicting Process," Journal of Physics: Conference Series, vol. 930, no. 1, pp. 1-7, 2017.

[4] S. P. Siregar and A. Wanto, "Analysis of Artificial Neural Network Accuracy Using Backpropagation Algorithm In Predicting Process (Forecasting)," International Journal of Information System \& Technology, vol. 1, no. 1, pp. 34-42, 2017.

[5] J. R. Saragih, M. Billy, S. Saragih, and A. Wanto, "Analisis Algoritma Backpropagation Dalam Prediksi Nilai Ekspor (Juta USD)," Jurnal Pendidikan Teknologi dan Kejuruan, vol. 15, no. 2, pp. 254-264, 2018.

[6] E. Hartato, D. Sitorus, and A. Wanto, "Analisis Jaringan Saraf Tiruan Untuk Prediksi Luas Panen Biofarmaka di Indonesia," Jurnal semanTIK, vol. 4, no. 1, pp. 49-56, 2018.

[7] S. Setti and A. Wanto, "Analysis of Backpropagation Algorithm in Predicting the Most Number of Internet Users in the World," JOIN (Jurnal Online Informatika), vol. 3, no. 2, pp. 110-115, 2018.

[8] R. E. Pranata, S. P. Sinaga, and A. Wanto, "Estimasi Wisatawan Mancanegara Yang Datang ke Sumatera Utara Menggunakan Jaringan Saraf," Jurnal semanTIK, vol. 4, no. 1, pp. 97-102, 2018.

[9] A. A. Fardhani, D. Insani, N. Simanjuntak, and A. Wanto, "Prediksi Harga Eceran Beras Di Pasar Tradisional Di 33 Kota Di Indonesia Menggunakan Algoritma Backpropagation,” Jurnal 
Infomedia, vol. 3, no. 1, pp. 25-30, 2018.

[10] J. Wahyuni, Y. W. Paranthy, and A. Wanto, "Analisis Jaringan Saraf Dalam Estimasi Tingkat Pengangguran Terbuka Penduduk Sumatera Utara," Jurnal Infomedia, vol. 3, no. 1, pp. 18-24, 2018.

[11] A. Wanto et al., "Levenberg-Marquardt Algorithm Combined with Bipolar Sigmoid Function to Measure Open Unemployment Rate in Indonesia," in Conference Paper, 2018, pp. 1-7.

[12] I. A. R. Simbolon, F. Yatussa'ada, and A. Wanto, "Penerapan Algoritma Backpropagation dalam Memprediksi Persentase Penduduk Buta Huruf di Indonesia," Jurnal Informatika Upgris, vol. 4, no. 2, pp. 163-169, 2018.

[13] S. P. Siregar, A. Wanto, and Z. M. Nasution, "Analisis Akurasi Arsitektur JST Berdasarkan Jumlah Penduduk Pada Kabupaten / Kota di Sumatera Utara," in Seminar Nasional Sains \& Teknologi Informasi (SENSASI), 2018, pp. 526-536.

[14] A. Wanto, "Optimasi Prediksi Dengan Algoritma Backpropagation Dan Conjugate Gradient Beale-Powell Restarts," Jurnal Teknologi dan Sistem Informasi, vol. 3, no. 3, pp. 370-380, Jan. 2018.

[15] B. K. Sihotang and A. Wanto, "Analisis Jaringan Syaraf Tiruan Dalam Memprediksi Jumlah Tamu Pada Hotel Non Bintang," Jurnal Teknologi Informasi Techno, vol. 17, no. 4, pp. 333346, 2018.

[16] M. A. P. Hutabarat, M. Julham, and A. Wanto, "Penerapan Algoritma Backpropagation Dalam Memprediksi Produksi Tanaman Padi Sawah Menurut Kabupaten/Kota di Sumatera Utara," Jurnal semanTIK, vol. 4, no. 1, pp. 77-86, 2018.

[17] Y. Andriani, H. Silitonga, and A. Wanto, "Analisis Jaringan Syaraf Tiruan untuk prediksi volume ekspor dan impor migas di Indonesia," Register - Jurnal Ilmiah Teknologi Sistem Informasi, vol. 4, no. 1, pp. 30-40, 2018.

[18] A. Wanto, "Penerapan Jaringan Saraf Tiruan Dalam Memprediksi Jumlah Kemiskinan Pada Kabupaten/Kota Di Provinsi Riau,” Kumpulan jurnaL Ilmu Komputer (KLIK), vol. 5, no. 1, pp. 61-74, 2018.

[19] I. S. Purba and A. Wanto, "Prediksi Jumlah Nilai Impor Sumatera Utara Menurut Negara Asal Menggunakan Algoritma Backpropagation,” Jurnal Teknologi Informasi Techno, vol. 17, no. 3, pp. 302-311, 2018.

[20] A. Wanto, "Prediksi Angka Partisipasi Sekolah dengan Fungsi Pelatihan Gradient Descent With Momentum \& Adaptive LR," Jurnal Ilmu Komputer dan Informatika (ALGORITMA), vol. 3, no. 1, pp. 9-20, 2019.

[21] N. Nasution, A. Zamsuri, L. Lisnawita, and A. Wanto, "Polak-Ribiere updates analysis with binary and linear function in determining coffee exports in Indonesia," IOP Conference Series: Materials Science and Engineering, vol. 420, no. 12089, pp. 1-9, 2018.

[22] A. Wanto, "Prediksi Produktivitas Jagung Indonesia Tahun 2019-2020 Sebagai Upaya Antisipasi Impor Menggunakan Jaringan Saraf Tiruan Backpropagation," SINTECH (Science and Information Technology), vol. 1, no. 1, pp. 53-62, 2019.

[23] B. Febriadi, Z. Zamzami, Y. Yunefri, and A. Wanto, "Bipolar function in backpropagation algorithm in predicting Indonesia's coal exports by major destination countries," IOP Conference Series: Materials Science and Engineering, vol. 420, no. 12089, pp. 1-9, 2018.

[24] A. Wanto et al., "Analysis of Standard Gradient Descent with GD Momentum And Adaptive LR for SPR Prediction," 2018, pp. 1-9.

[25] M. Magister et al., "Efektivitas Penerapan Sanksi Denda E-Tilang Bagi Pelanggar Lalu Lintas Berdasarkan Undang-Undang Nomor 22 Tahun 2009 Tentang Lalu Lintas Dan Angkutan Jalan (Studi Di Polres Rembang)," Hukum Khaira Ummah, vol. 12, no. 4, pp. 754-766, 2017.

[26] Y. A. Lesnussa, S. Latuconsina, and E. R. Persulessy, "Aplikasi Jaringan Saraf Tiruan Backpropagation untuk Memprediksi Prestasi Siswa SMA ( Studi kasus: Prediksi Prestasi Siswa SMAN 4 Ambon )," Jurnal Matematika Integratif, vol. 11, no. 2, pp. 149-160, 2015. 